\title{
Nódulo pulmonar esquistossomótico simulando neoplasia: relato de caso
}

\author{
Pulmonary schistosomotic nodule simulating neoplasia: case report \\ Marcelo Cunha Fatureto', Dalmo Correia ${ }^{2}$, Márcia Benedita de Oliveira Silva ${ }^{3}$, Maria Fernanda Curi Barra ${ }^{4}$, \\ Andreza Vargas da Silva ${ }^{4}$, Daniela Chaves Tarquinio ${ }^{4}$, Kátia Delalíbera Pacheco ${ }^{4}$ \\ e Marcus Aurelho Lima ${ }^{5,6}$
}

Resumo Paciente sadio em que, ao exame de rotina, foi detectado nódulo pulmonar esquistossomótico com verme adulto, 25 anos após o tratamento específico com oxamniquine ${ }^{\circledR}$ e distante da região endêmica. O nódulo simulava clinicamente neoplasia.

Palavras-chaves: Pulmão. Esquistossomose. Granuloma. Neoplasia. Patologia.

Abstract Healthy patient in which during ordinary examination a pulmonary schistosomotic nodule with an adult parasite, was detected 25 years far from endemic region and after specific treatment with oxamniquine ${ }^{\circledR}$. Clinically the nodule simulated neoplasia.

Key-words: Lung. Schistosomiasis. Granuloma. Neoplasia. Pathology.

O envolvimento pulmonar na esquistossomose é incomum, mas tem sido descrito em populações que habitam zonas endêmicas, como várias regiões da África, Ásia, América do Sul e llhas do Caribe, é usualmente caracterizado por forma miliar ou por infiltrados nodulares difusos e, na maioria dos casos, está associado a comprometimento clínico aparente de outros órgãos ${ }^{10}$. As lesões pulmonares da esquistossomose manifestam-se, freqüentemente, na forma granulomatosa ou tubérculos dispersos difusamente ao redor de bronquíolos e alvéolos e, raramente, ocorre lesão solitária circunscrita.
A detecção de um nódulo solitário merece ser questionada quanto aos diagnósticos diferenciais, como carcinoma e tuberculose pulmonar. Em revisão de literatura, não se verificou qualquer relato da presença do verme adulto nos pulmões de seres humanos.

Tendo em vista o exposto, relata-se caso de homem com o achado de nódulo pulmonar granulomatoso (verme adulto de Schistosoma mansoni) após 25 anos ter sido tratado da forma hepatointestinal e distante da região endêmica.

\section{RELATO DO CASO}

$\mathrm{JI}$, masculino, 47 anos, natural de Belo Horizonte e procedente de Uberaba, técnico industrial, hipertenso, assintomático. Em exame periódico de rotina, foi evidenciada na radiografia de tórax, consolidação tênue em quadrante superior direito (Figura 1). A tomografia computadorizada (TC) detectou nódulo pulmonar com reforço significativo após contraste venoso em lobo superior direito, sugerindo neoplasia, sem linfonodopatia mediastinal
(Figura 2). Os exames físico e laboratoriais eram normais. Com a hipótese de neoplasia, foi submetido à nodulectomia por ressecção em cunha com biópsia por congelação, que revelou granuloma, sem evidências de neoplasia.

À macroscopia, fragmento de pulmão pesando $4 \mathrm{~g} \mathrm{e}$ que media $2,5 \times 2,5 \times 2,0 \mathrm{~cm}$, sem continuidade com a pleura, onde se notou área circular com diâmetro de $0,5 \mathrm{~cm}$, avermelhada, aparentemente necrótica, pardo-clara,

\footnotetext{
1. Disciplina de Cirurgia Torácica da Faculdade de Medicina do Triângulo Mineiro,Uberaba, MG 2. Disciplina de Doenças Infecciosas e Parasitárias da Faculdade de Medicina do Triângulo Mineiro, Uberaba, MG 3 . Disciplina de Parasitologia da Faculdade de Medicina do Triângulo Mineiro, Uberaba, MG 4 . Acadêmicas do Curso de Medicina da Faculdade de Medicina do Triângulo Mineiro, Uberaba, MG, 5.Disciplina de Endocrinologia da Faculdade de Medicina do Triângulo Mineiro, Uberaba, MG. 6. Laboratório de Anatomia Patológica do Hospital Dr. Hélio Angotti da Associação de Combate ao Câncer do Brasil Central, Uberaba, MG. Endereço para correspondência: Dr. Dalmo Correia. Faculdade de Medicina do Triângulo Mineiro/FMTM. Av. Getúlio Guaritá s/n, Caixa Postal 118, 38025-440 Uberaba, MG, Brasil.

Tel: $553433185255 / 33185279$

e-mail: dalmo@mednet.com.br

Recebido para publicação em 16/5/2003

Aceito em 4/9/2003
} 
circundada por halo de tecido pálido. À microscopia, notava-se parênquima pulmonar com infarto recente com processo inflamatório agudo e crônico granulomatoso e estrutura parasitária necrótica compatível com verme adulto de Shistosoma mansoni, além de pneumonia crônica discreta em organização e vasculite crônica (Figuras 3 e 4).

Reavaliando a história pregressa do paciente, constatou-se que há 25 anos tomava banhos na Lagoa da Pampulha em Belo Horizonte e foi tratado com Oxamniquine (Mansil $^{\circledR}$ ) devido a quadro de
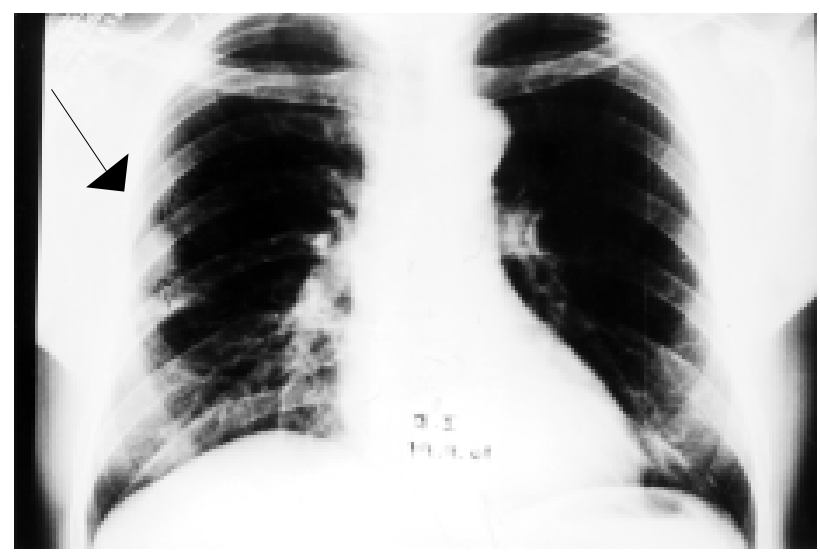

Figura 1- Radiografia de tórax com consolidação tênue periférica em lobo superior direito.

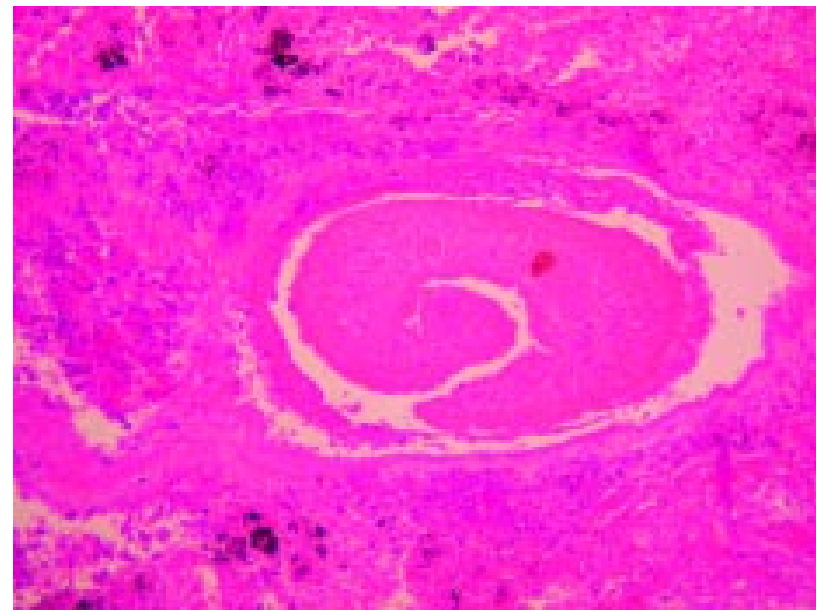

Figura 3 - Parênquima pulmonar apresentando veia contendo verme adulto de S. mansoni na sua luz, circundada por infarto recente (HE 100X). esquistossomose hepatointestinal, sendo considerado curado em reavaliações subseqüentes. Na avaliação atual foram realizadas cinco análises fecais seriadas (Kato-Katz) e não se identificou ovos de parasitas. A ultrassonografia abdominal não evidenciou fibrose periportal distal, dilatação de veia porta ou alteração do fluxo sangüíneo. Várias radiografias torácicas periódicas prévias não mostraram alteração. O pósoperatório foi normal. O paciente está assintomático sob controle ambulatorial da doença e sem tratamento específico.

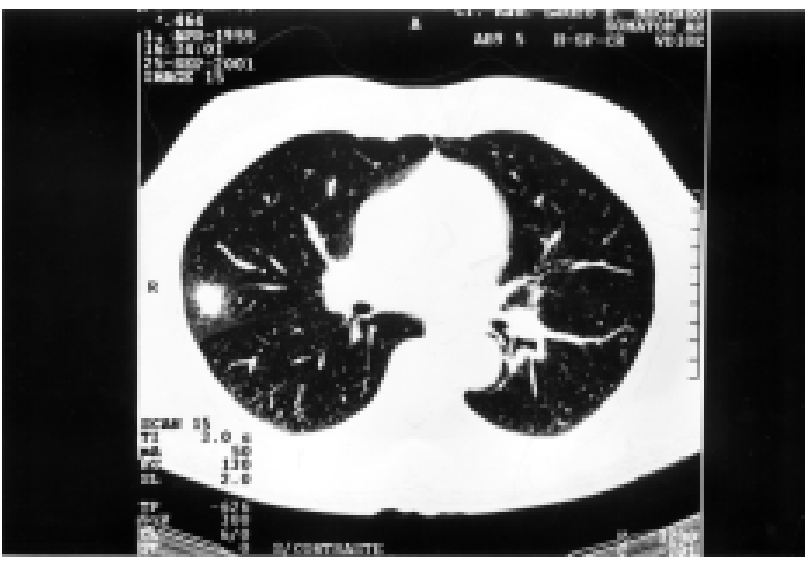

Figura 2 - Tomografia computadorizada de tórax: nódulo pulmonar solitário à direita.

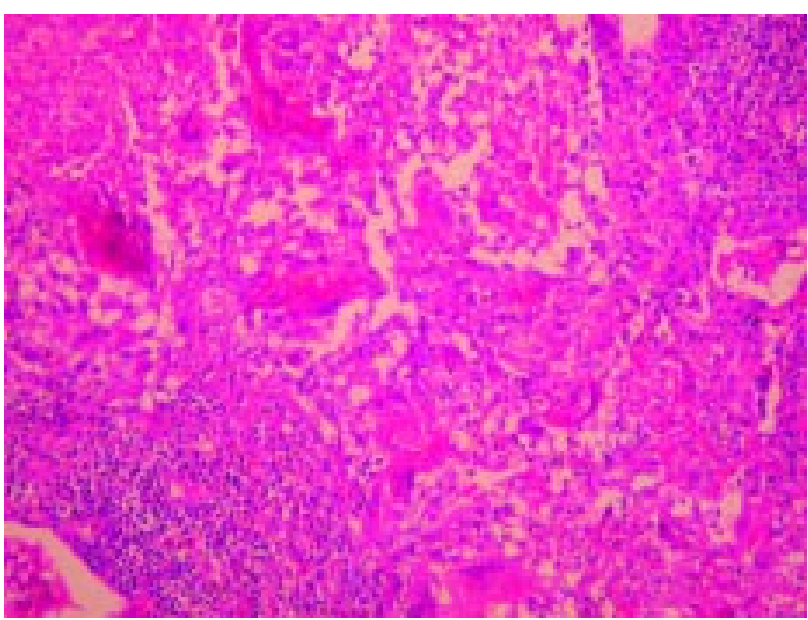

Figura 4 - Área adjacente ao infarto pulmonar com pneumonia crônica discreta em organização (HE 200X).

\section{DISCUSSÃO}

O nódulo pulmonar solitário é observado em 0,09 a $020 \%$ de todos os exames radiográficos de tórax. Estimativas norte-americanas calculam que sejam identificados cerca de 150.000 nódulos por ano. Embora as causas incluam muitas condições benignas, o carcinoma broncogênico, como causa de nódulo solitário tem aumentado, especialmente em idosos ${ }^{8}$

Trata-se de forma pulmonar da esquistossomose mansônica em paciente há 25 anos sem contato com 
áreas de habitat natural do parasita e que fora tratado para a forma hepatointestinal.

O envolvimento pulmonar na esquistossomose mansoni é incomum mas tem sido descrito em populações que habitam zonas endêmicas. A migração anormal de ovos ou de parasitas (mais raramente) de S. mansoni do sistema porta, por meio de anastomoses porto-cava, resulta em deposição ectópica no leito vascular pulmonar ${ }^{2}{ }^{7}$. Assim, os pulmões podem ser acometidos usualmente de duas formas: 1) migração de esquistossomas para o pulmão produzindo reação tóxica tênue com áreas ocasionais de consolidação pulmonar; 2) embolia de ovos e, raramente, de formas adultas levando à fibrose pulmonar na fase tardia da doença ${ }^{1} 23^{4} 6$. A esquistossomose mansoni raramente cursa com nódulo pulmonar isolado. O nódulo pulmonar solitário é uma entidade radiológica que traduz inúmeras possibilidades clínicas, inclusive o carcinoma broncogênico, fato que torna imperiosa uma conduta diagnóstico-terapêutica eficaz, já que o prognóstico do câncer de pulmão depende do seu diagnóstico precoce. O nódulo pulmonar indeterminado deve ser submetido à ressecção para elucidação diagnóstica e tratamento adequado ${ }^{5}$, como ocorreu no presente caso. A tomografia computadorizada de tórax sugeriu neoplasia pelo aumento significativo da densidade após infusão de contraste venoso.
Há relato na literatura de nódulo pulmonar isolado em paciente adulto, cinco anos após tratamento de seminoma testicular. A exemplo do ocorrido neste relato, houve simulação de metástase de seminoma. Dentre os diagnósticos diferenciais foram postuladas causas infecciosas (fúngicas, bacterianas, virais e micobacterianas), malígnas (metástases, linfomas, granulomatose linfomatóide), vasculares (embolia), inflamatórias, auto-imunes e ambientais ${ }^{9}$.

As lesões pulmonares na esquistossomose geralmente apresentam-se como micronódulos (tubérculos) difusos bilaterais ou eventualmente em forma de fibrose pulmonar difusa e hipertensão pulmonar em fases tardias. As lesões provocadas pelos ovos são, inicialmente, um rico exsudato que é progressivamente substituído por tecido conjuntivo até a formação de um nódulo fibrótico ${ }^{12}$. A partir da $2^{a}$ oviposição, os granulomas tendem a ser menores. Os granulomas podem ser do tipo exsudativo, exsudativonecrótico, produtivo ou fibróticos. Nódulo pulmonar esquistossomótico é excepcional e os relatos destes são escassos na literatura.

Atualmente, os recentes avanços das técnicas para investigação diagnóstica por imagem como tomografia computadorizada com emissão de prótons e com densitometria, têm permitido uma abordagem menos invasiva para diferenciação entre nódulos benignos e malignos $^{8}$.

\section{REFERÊNCIAS BIBLIOGRÁFICAS}

1. El Mallah $\mathrm{SH}$, Hashem M. Localized bilharzial granuloma of the lung simulating a tumor. Thorax 8: 148-151, 1953.

2. Erfan M. Pulmonary shistosomiasis. Transactions of the Royal Society of Tropical Medicine \& Hygiene 42: 109-116, 1948.

3. Fleming CM, Shepard JO, Mark EJ. A 47-year-old Man with Waxing and Waning Pulmonary Nodules Five Years after Treatment for Testicular Seminoma. The New England Journal of Medicine 348; 20: 2019-2027, 2003.

4. Greco DB, Pedroso ER, Lambertucci JR, Rocha MO, Coelho $\mathrm{PM}$, Raso P, Ferreira CS. Pulmonary involvement in shistosomiasis mansoni. Memórias do Instituto Oswaldo Cruz 82 (Suppl 4): 221-227, 1987.

5. Jaffé R, Mayer M, Pifano CF. Biological and pathological studies in animals infested with male Schistosoma mansoni. Abstract of Tropical Disease Bulletin, 46: 756, 1949

6. Jawahiry KI, Karpas CM. Pulmonary schistosomiasis: a detailed clinicopathologic study. Am. Review of Respiratory Disease, 88: 517-527, 1963.
7. Neves DP, Melo AL, Genaro O, Linardi PM. Parasitologia Humana $10^{\circ}$ edição cap. 22, p.174-180, 2000.

8. Ost D, Fein AM, Feinsilver SH. The solitary pulmonary nodule. The New England Journal of Medicine 348; 25: 2535-2542, 2003.

9. Pedroso ER, Lambertucci JR, Greco DB, Rocha OC, Ferreira CS, Raso P. Pulmonary schistosomiasis mansoni: post-treatment pulmonary clinical-radiological alterations in patients in the chronic phase: a double-blind study. Transactions of the Royal Society of Tropical Medicine \& Hygiene 81: 778-81, 1987.

10. Schaberg T, Rahn W, Racz P, Lode H. Pulmonary schistosomiasis resembling acute pulmonary tuberculosis. European Respiratory Journal 4: 1023-1026, 1991

11. Schwartz E, Rozenman J, Perelman M. Pulmonary manifestions of early shistosome infection among nonimmune travelers. The American Journal of Medicine 109: 718-722, 2000.

12. Tizes R, Zaki MH, Minkowitz S. Pulmonary schistosomiasisReport of a case found with a solitary lesion. The American Journal of Tropical Medicine and Hygiene 16: 595-597, 1967. 